\title{
Gonadotropin-releasing Hormone-containing Neurons Change Size with Reproductive State in Female Haplochromis burtoni
}

\author{
Stephanie A. White and Russell D. Fernald \\ Neuroscience Program, Stanford University School of Medicine, Stanford, California 94305-2130
}

In the preoptico-hypothalamic area (POA) of teleost fish, neurons containing gonadotropin-releasing hormone (GnRH) regulate reproduction through direct projections to pituitary gonadotropes. Here we show that these GnRH-containing cells change size depending on the reproductive and maturational state in female Haplochromis burtoni. We selected animals prior to, during, and after the reproductive portion of their life history, in both brooding and spawning states. Immunocytochemical staining of GnRH-containing neurons in the POA revealed that these cells are up to twice as large in females that have never spawned or are in the act of spawning than they are in females that are carrying broods. Older, postreproductive females have the largest cell sizes. Previous work on male $\boldsymbol{H}$. burtoni has shown that soma sizes of the homologous neurons change according to social status, with dominant fish having larger cells than subordinates. Since reproductively active females have no apparent social hierarchy and are all exposed to approximately the same external stimuli, the primary factor(s) controlling GnRH-immunoreactive (irGnRH) neuron size appears to be internal reproductive state. Thus, while irGnRH neurons are pleiomorphic in both males and females, cell size change is differently regulated in each.

[Key words: gonadotropin-releasing hormone, plasticity, reproduction, female, teleost, cichlid, dimorphism, regulation]

In many vertebrate species, distinct differences in the nervous system that exist between males and females are thought to arise through two processes: (1) the organizational and (2) the activational effects of sex steroids (Phoenix et al., 1959). Organizational influences occur during the fetal-prepubertal period and result in structural differences in the brain. In the sexually mature animal, these anatomical dimorphisms form the basis for differential activation of male and female reproduction by sex steroids. A striking manifestation of these regulatory dimorphisms is the cyclical pattern of reproduction in females versus a tonic state in males (Harris, 1964). Recently, strict distinctions

\footnotetext{
Received Apr. 22, 1992; revised June 17, 1992; accepted July 17, 1992.

We thank B. Evans, R. Francis, S. McConnell, M. Nadal-Vicens, and R. Sapolsky for helpful comments on the manuscript, and G. McRoberts and R. Francis for statistical consultations. This research was supported by National Institutes of Health Predoctoral Fellowship MH09986 and the Scottish Rite Foundation (S.A.W.) and by NIH Grant HD23799 (R.D.F.).

Correspondence should be addressed to Stephanie A. White, Department of Psychology, Jordan Hall, Building 420, Stanford University, Stanford, CA 943052130.

Copyright (C) 1993 Society for Neuroscience $0270-6474 / 93 / 130434-08 \$ 05.00 / 0$
}

between organizational and activational cffects have bcgun to blur due to the discovery that steroid regulation in adults often includes structural remodeling (cf. Arnold and Breedlove, 1985; Naftolin et al., 1990; McEwen et al., 1991).

Sexual dimorphisms of brain nuclei include differences in neuronal number, size, density, and synaptic connections. In vertebrates, three well-characterized dimorphisms illustrate the typical interplay between structural and regulatory actions of gonadal steroids: (1) the robust nucleus of the archistriatum in zebra finches, which mediates the motor production of song (Konishi and Akutagawa, 1985, 1990); (2) the laryngeal motor neurons in Xenopus laevis, which also control courtship song (Kelley and Tobias, 1989); and (3) the spinal nucleus innervating the bulbocavernosus muscles, which facilitate copulation in the rat (Breedlove, 1986; Araki et al., 1991). In each case, these anatomical structures, which subserve male-specific reproductive behaviors, are larger in malcs duc to carly exposure to androgens. Without androgens, the homologous cells in females either atrophy or die. Interestingly, administration of androgens to adult females causes masculinization of the cytoarchitecture, showing that the structural effects of gonadal steroids set up early in development can be perturbed in the mature animal (Gurney, 1981; Arnold, 1984; Breedlove, 1986; Kelley and Tobias, 1989).

Other dimorphisms do not simply involve cell preservation in one sex and cell death in another. Instead, a more complex relationship between gender and cellular morphology exists. For example, neuronal populations within the ventromedial and arcuate nuclei of the female rat exhibit plasticity of dendritic arborization and cell membrane composition, respectively (Pfaff and McEwen, 1983; Naftolin et al., 1990). These hypothalamic nuclei are involved in female reproduction, and in each case, the observed morphological changes occur cyclically, in phase with the $4 \mathrm{~d}$ estrous cycle (Garcia-Segura et al., 1988; Frankfurt et al., 1990). Such plasticity suggests that the structural dimorphisms set up during fetal and peripubertal periods lead to regulatory dimorphisms in adults, which in females can then induce further structural changes (Naftolin et al., 1990).

Recently, work on the African cichlid fish, Haplochromis burtoni, has revealed a unique plasticity in a population of hypothalamic neurons known to control reproduction. Specifically, gonadotropin-releasing hormone (GnRH)-containing neurons in a discrete portion of the male hypothalamus are plastic with respect to soma size (Davis and Fernald, 1990; Francis et al., in press). In this species, males are either territorial or nonterritorial. Soma size correlates with these two states as follows. Territorial males are dominant and aggressive, are reproductively active, and have large GnRH-containing neurons in the 
preoptico-hypothalamic area (POA), a cell population known to project to pituitary gonadotropes. In contrast, nonterritorial males are less aggressive, do not reproduce, and have smaller POA GnRH neurons (Davis and Fernald, 1990). These differences exhibit pronounced plasticity: experimental manipulation of the social environment can provoke a transition from one social status to the other, and this leads to corresponding changes in cell size (R. C. Francis and R. D. Fernald, unpublished observations).

Here we ask whether GnRH neurons in female H. burtoni are similarly plastic and, if so, what regulates cell size. Mature female $H$. burtoni lay eggs and then take them into their mouths for fertilization and brooding (Fernald, 1977). Broods are carried for circa 2 weeks prior to being released. Females that are ready to spawn will have enlarged abdomens, due to the presence of ripe eggs. At a different point in the cycle, females with distinctively large mouth cavities filled with fry are not ready to spawn and avoid males.

Since females do not engage in the aggressive social interactions that regulate male GnRH cell size, it is possible that they do not show the same plastic changes. GnRH cell size would then be sexually dimorphic, increasing in females simply as a function of development and becoming stable at maturity. This would contrast with the life-long potential for plasticity seen in males. Alternatively, since GnRH cell size in males is correlated with both social and reproductive status, cell size in females might fluctuate according to the female reproductive cycle, comparable to the changes in rat hypothalami, described above. In this study, we therefore assess GnRH soma size plasticity in female $H$. burtoni at different stages in their life history, by examining any correlations between soma size and reproductive and/or maturational states of the fish. A strict allometric relationship between soma and body size would indicate that cell plasticity in females is simply a function of overall growth. Any deviations would indicate that other regulatory mechanisms, in addition to body growth, are acting at the GnRH neuron. If female GnRH cell sizes do change, we could use soma size as an assay to explore the signals that govern female reproduction and thereby elucidate any regulatory dimorphisms in the POA of male and female fish.

\section{Materials and Methods}

\section{Subjects}

Maintenance. Fish used in these studies were bred and reared at the University of Oregon, and later transported to the laboratory at Stanford. They were acclimated to their new environment for a minimum of 2 months prior to these experiments. In each setting, fish were maintained in aquaria designed to mimic the conditions of their natural environment in Lake Tanganyika, Africa (Fernald and Hirata, 1977): temperature of $29^{\circ} \mathrm{C}, \mathrm{pH} 8.0$, and $12 \mathrm{hr} / 12 \mathrm{hr}$ light/dark cycle with fullspectrum illumination (Spectralight, $30 \mathrm{~W}$ ). Fish were fed once daily on cichlid chow (Wardley). Tank communities consisted of both males and females typically in a ratio of 3:11. Gravel and terracotta pot shards were provided to allow dominant males to establish and maintain territories, an integral part of reproductive behavior as previously described (Fernald, 1977).

Experimental groups. Fish were observed on a twice-daily basis (15 min each) to determine their reproductive status. Females from five different reproductive and maturational states were examined: virgins, first (1st) brooders, experienced spawners, experienced brooders, and postreproductive fish. Table 1 summarizes the criteria used in defining these groups.

Virgins and 1st brooders represent animals prior to and at the onset of reproductive activity. Females carrying their first brood (1 st brooders) were identified and their eggs were staged as described below. Fish in

\begin{tabular}{|c|c|c|}
\hline Category & $\begin{array}{l}\text { Age } \\
\text { group }\end{array}$ & Description \\
\hline Virgin & $\mathbf{I}$ & $\begin{array}{l}<6 \text { months old; has not spawned, } \\
\text { although age-mates have }\end{array}$ \\
\hline Ist brooder & I & $\begin{array}{l}<6 \text { months old; has carried first } \\
\text { brood for } \sim 2 \text { weeks }\end{array}$ \\
\hline $\begin{array}{l}\text { Experienced } \\
\text { spawner }\end{array}$ & II & $\begin{array}{l}>1 \text { year old; has just commenced } \\
\text { egg-laying }\end{array}$ \\
\hline $\begin{array}{l}\text { Experienced } \\
\text { brooder }\end{array}$ & II & $\begin{array}{l}>1 \text { year old; has carried most } \\
\text { recent brood for } \sim 2 \text { weeks }\end{array}$ \\
\hline $\begin{array}{l}\text { Postreproductive } \\
\text { female }\end{array}$ & III & $\begin{array}{l}\gg 1 \text { year old; has not spawned in } \\
\text { over } 4 \text { months; exhibits some } \\
\text { territorial behaviors }\end{array}$ \\
\hline
\end{tabular}

this group were killed $14 \mathrm{~d}$ after fertilization was determined to have taken place, coincident with the end of a typical $H$. burtoni brooding period. Nonspawning age-mates, that is, "virgins," were taken from the same tank and conjointly processed. Thus, from within the same age group, females that had reproduced and carried their broods for 2 weeks were compared with those yet to do so. Such a comparison was intended to identify any neuroendocrine changes associated with the initial activation of female reproductive behavior.

A different pre- and postreproduction comparison was made between older groups of fish, that is, experienced spawners and experienced brooders. These more mature fish ( $>1$ year of age) had already been reproductively active. Experienced spawners were spawning females caught and killed at the onset of egg-laying. Experienced brooders were females who had just carried their most recent broods to maturity as determined by egg staging (see below) and, as such, were the older counterpart to ist brooders. In these older groups, a comparison of neuroendocrine status could be made within a single reproductive cycle rather than across a maturational transition. In addition, any effect of previous reproductive experience on the brain-pituitary-gonadal system could be identified by comparing younger and older fish.

Postreproductive females comprised the last group, chosen to represent a late life history stage. These females were never observed to spawn over a minimum period of 4 months and, consequently, were without eggs throughout the study. In addition, they exhibited behaviors more typical of socially dominant males (Fernald, 1977), including transient eyebar display (unrelated to any reproductive behavior), territoriality, butting of other females and nonterritorial males, and occasional fighting with dominant males.

\section{Protocol}

Staging. A female with eggs in her mouth was swiftly netted and gently coaxed to release a few eggs into a Petri dish. The fish was tagged by clipping a part of its caudal or dorsal fin prior to returning it to the tank. Stress associated with this procedure was limited by minimizing handling of the animals ( $<1$ min duration). That females continued to brood their remaining eggs rather than releasing them prematurely is further indication that little stress was experienced. The developmental stage of the released eggs was determined with the aid of a dissecting microscope (120x) according to the criteria of Hagedorn and Fernald (1992). Fourteen days after fertilization was determined to have taken place, females were killed. Broods were examined to reconfirm that only fcmales whose progeny appeared ready for release were included.

Tissue collection. Fish were killed and weighed, and their standard lengths (SL) were measured. Ovaries, if present, were removed, examined, and weighed, and brains were processed for antibody staining (see below).

\section{Histology}

Following death, adult brains were rapidly removed from the head and immersion fixed for $6-8 \mathrm{hr}$ (4\% paraformaldehyde in $0.2 \mathrm{M} \mathrm{NaPO}_{4}, \mathrm{pH}$ 
7.4) at room temperature. For young fish, entire heads were fixed for up to $20 \mathrm{hr}$. The whole brain was cryoprotected overnight at $4^{\circ} \mathrm{C}$ in $30 \%$ sucrose, frozen at $-20^{\circ} \mathrm{C}$, and then sagittally sectioned at $40 \mu \mathrm{m}$. Two sets of brain sections were generated per fish by mounting adjacent sections onto gelatin-subbed slides in an alternating sequence. Sections were kept frozen at $-20^{\circ} \mathrm{C}$ until staining. Immunoreactive $\mathrm{GnRH}$ (irGnRH) cells were labeled with a primary antibody to GnRH (see below) and visualized via a 3,3'-diaminobenzidine reaction (Davis and Fernald, 1990).

A quota of 50 measurements per fish, roughly equivalent to onefourth of the total preoptic GnRH neuron pool (Davis and Fernald, 1990), was selected as a minimum sample number for gauging mean soma size. In most cases, this quota was achieved by processing sections from the first set of adjacent sections only. When necessary, sections from the alternate set werc processed in a second immunostain. In these cases, measurements from the two stains were kept separate until statistical tests demonstrated that the data could be pooled (see Statistics, below).

To identify the GnRH cells, a commercial antibody to synthetic mammalian luteinizing hormone-releasing hormone (LHRH) was used (Incstar Corp., Stillwater, MN). However, since previous studies on male $H$. burtoni conducted in our laboratory had used an antibody to salmon GnRH, GF-6 (courtesy of N. Sherwood, University of Victoria, British Columbia; Davis and Fernald, 1990), we wanted to ensure that the same populations of preoptic GnRH cells were being stained in all cases. Therefore, brain sections from one fish at each reproductive stage as well as from a dominant male were processed using both antisera. Statistical analyses (see below) demonstrated that irGnRH neurons in the POA did not differ significantly in size as a function of antibody type. In both sets of tissue sections, fibers emanating from stained POA cells traveled to the pituitary and mean soma sizes obtained from the dominant male were comparable with those previously reported (Francis et al., 1922). These findings indicate that the same cell population was being labeled within the POA by the two antibodies, namely, that which regulates gonadotropin release from the pituitary.

Interestingly, differences in staining between the two antisera are apparent in GnRH-containing cells outside of the POA. Specifically, GnRH populations in the nervus terminalis and mesencephalic region were clearly visualized with the anti-salmon antibody but were faint to invisible with the anti-mammalian LHRH stain. This observation raises the intriguing possibility that other forms of GnRH peptides are active in the H. burtoni brain.

\section{Cell measurements}

Soma sizes of irGinRH neurons in the POA were measured using computer-captured video images (IMAGE, version 1.40, by Wayne Rasband, NIH) from a microscope (Zeiss, $600 \times$ ). First, the total number of nucleated irGnRH neurons per section was counted. Then, the two-dimensional area was calculated for those stained cells that fulfilled the following criteria: (1) the cell was in the POA, (2) its perimeter was discernable, and (3) its nucleus was in the plane of section. Outlines of stained cells were traced by moving a mouse-controlled eraser tool along the video image to remove all cell processes. Since antibody staining incompletely labeled cell processes, we could not reliably identify and compare any dendritic changes. To aid in accuracy, the trace was visually compared both to the unedited video image and to the appearance of the cells under the microscope. To estimate the error associated with this technique, cell measurements were repeated on several fish. Differences in average soma sizes obtained from repeated measurements on the same fish were small, averaging less than $10 \%$.

\section{Statistics}

Statistical analyses were computed either by hand according to Siegel (1956) or using STATVIEW II software (Abacus Concepts, Inc). Mean soma sizes obtained from different stains were compared to determine whether these measurements could be pooled for each fish. In cases where two anti-mammalian LHRH immunostains were required, a Wilcoxon signed-rank test revealed no significant differences between mean soma sizes measured in the first stain (set A) and those from the second (set $\mathrm{B} ; p>0.05$ ). Furthermore, there was no significant difference between cell sizes measured using the commercial antibody to mammalian LHRH and those measured using the anti-salmon antibody, GF-6 $(p>0.05)$. Cell measurements from all of the stains were therefore pooled and their means calculated.
A preliminary analysis of all subjects revealed significant differences in irGnRH neuron size between groups. To discover whether differences in fish body size contributed to these differences, correlations between mean soma size and standard length (SL) were made using a Spearman rank test. This showed that for all subjects combined, there was a positive correlation between SL and mean soma size $(r=0.834)$. In order to assess directly the relationship between reproductive status and soma size, effects of body size were factored out as follows. First, the contribution of SL to soma size was calculated using $R^{2}$ from the Spearman rank tests. Mean soma sizes were then corrected using the formula SS $+\left\{\left[\left(\mathrm{SS} \times \mathrm{SL}_{X} / \mathrm{SL}\right)-\mathrm{SS}\right] \times K\right\}$, where $\mathrm{SS}$ is the uncorrected mean soma size of an individual fish, $\mathrm{SL}$ is its standard length, and $\mathrm{SL}_{X}$ is the mean standard length for the subject pool under comparison. $K$ is a constant for the contribution of SL to soma size as determined by the Spearman rank test for that sample. Thus, for $K=0$, there would be no dependence of soma size on SL. For $K=1$, differences in soma size would be fully attributable to differences in body size, and soma size would simply be nomialized for SL. Mean standard lengths ( $\left.\mathrm{SL}_{X}\right)$, constants $(K)$, as well as corrected soma sizes were calculated for each set of comparisons.

Corrected soma sizes of different reproductive groups were compared using Mann-Whitney $U$ tests for two groups and two-tailed probabilities were calculated. Kruskal-Wallis analysis was used to compare three or more groups. Significance levels were set at $p<0.05$. Finally, gonosomatic indices (GSIs) were calculated for each fish as the ratio of gonadal to body weight $\times 100$.

\section{Results}

\section{irGnRH neuron soma sizes}

This study explores whether POA neurons containing GnRH change in size during the following reproductive and maturational stages in the life history of female $H$. burtoni: virgins, 1 st brooders, experienced spawners, experienced brooders, and postreproductive fish. The main result from these experiments is that irGnRH cell size is highly correlated with female reproductive state. Figure 1 shows a representative set of POA irGnRH neurons from an experienced brooder and an experienced spawner. This illustrates the difference in cell soma size between fish of similar age but in different reproductive states: soma sizes in spawning females are typically twice as large as those in females carrying broods.

Mean soma size also changes with age: cells in females younger than 6 months (class I) are smaller than mature females (class II), and these, in turn, are smaller than the oldest females (class III). To discover whether age-related differences in fish body size were contributing to the observed differences in cell size, correlations between SL and cell size were assessed. Statistical tests revealed that, for all subjects combined, there is a positive correlation $(r=0.834)$ between SL and mean soma size. To assess more directly the relationship between reproductive state and soma size, the contribution of SI, to soma size was factored out (see Materials and Methods). Figure 2 shows both the original mean soma sizes and those corrected for SL for all groups. The differences in both uncorrected (Fig. $2 A$ ) and corrected (Fig. $2 B$ ) mean soma size as a function of the reproductive state of the fish reveal that body size variability does not account for all of the observed changes.

Statistical analyses were repeated using the corrected means and are summarized in Table 2. These confirm that preoptic irGnRH cell size varies depending on reproductive state, both within and across age groups. Within age class I, irGnRH cell soma sizes are smaller in 1st brooders than in virgins with a trend toward significance ( $p=0.056)$. In age class II, irGnRH cell soma sizes in experienced brooders are significantly smaller than those in experienced spawners. Postreproductive fish have the largest cells. However, with body size factored out, there is 

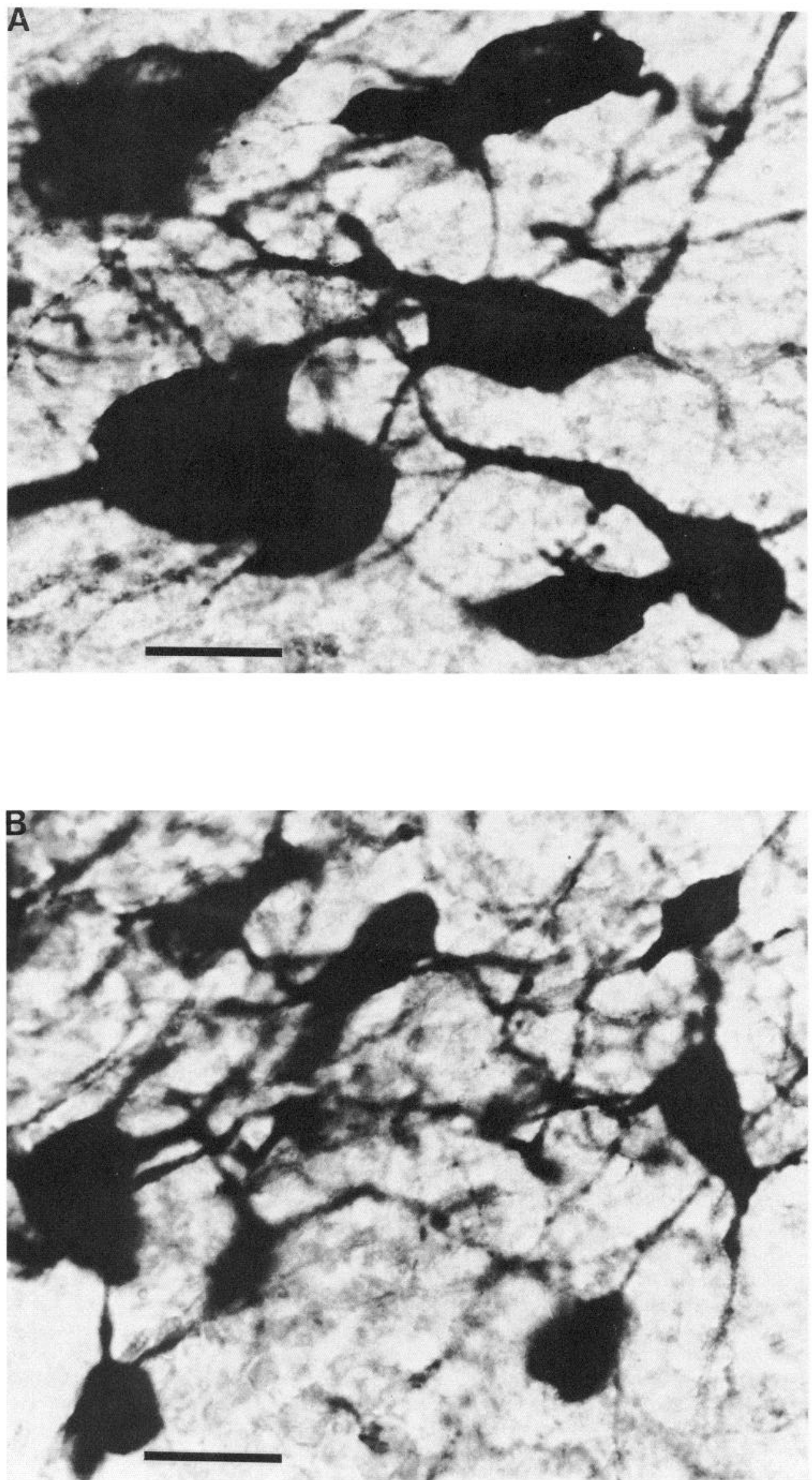

Figure 1. Photomicrograph showing irGnRH cells in spawning $(A)$ and brooding $(B)$ fish. irGnRH cells were labeled with a primary antibody to $\mathrm{GnRH}$ and visualized via a 3,3'-diaminobenzidine reaction (see Materials and Methods). Scale bars, $20 \mu \mathrm{m}$. 


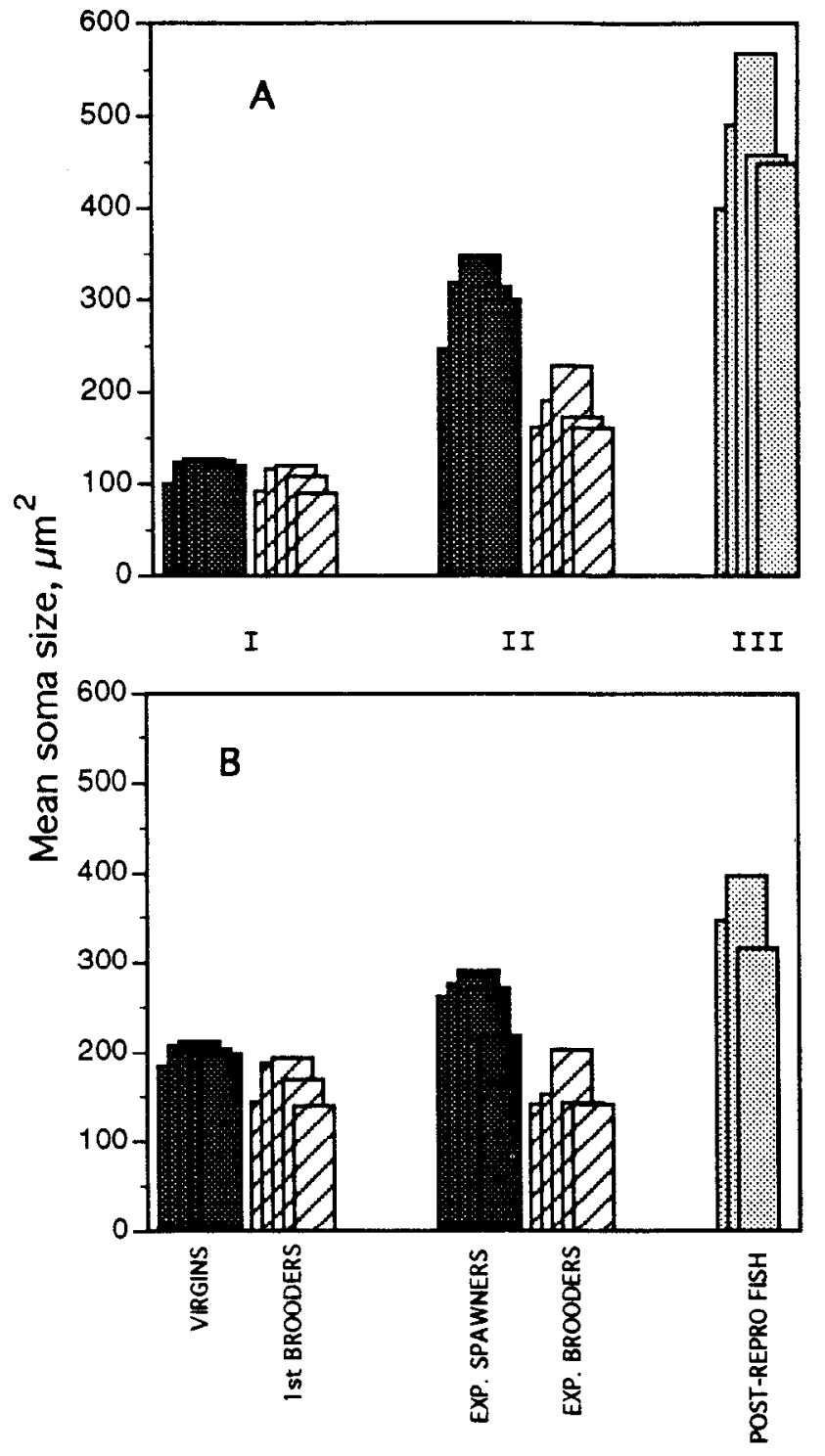

Reproductive status by age group

Figure 2. irGnRH soma sizes differ depending on age and reproductive state. $A$ shows the raw data for soma size plotted as a function of reproductive state. $B$ shows the same data corrected to account for the contribution of body size to soma size differences when all groups are compared (see Materials and Methods). There are five fish per group except for the postreproductive fish $(B)$, for which there are only three. SEMs are less than $5 \%$ for fish in agc class $I$, and less than $10 \%$ for agc classes II and III.

no longer a significant difference in soma size between fish of similar reproductive status despite age and experience differences: corrected irGnRH soma sizes in virgins do not significantly differ from those in experienced spawners; somas in 1st brooders are the same size as those in experienced brooders.

These results raise the possibility that irGnRH ncurons grow throughout the female $H$. burtoni life-span, except during the 2 week brooding period, when they contract. If so, then soma sizes in all nonbrooding fish should be similar, once corrected for maturational growth. To test this hypothesis, cell measurements, corrected for SL, from postreproductive fish were added for comparison with those from experienced spawners and virgins. Kruskal-Wallis analysis revealed significant differences be-

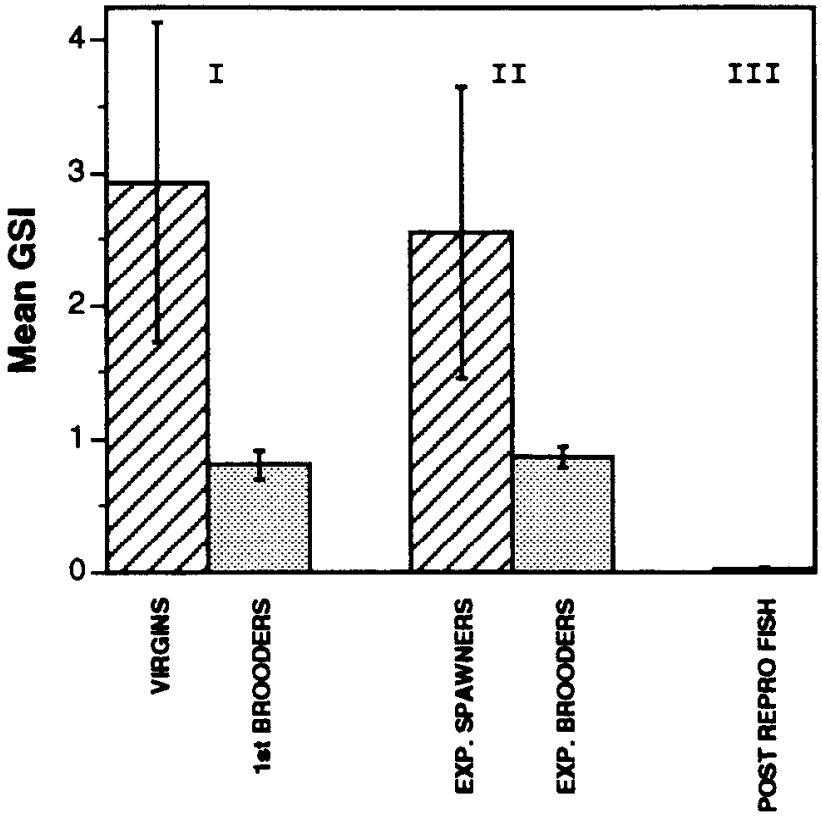

Reproductive status by age group

Figure 3. GSI as a function of reproductive state. GSIs were calculated for each fish as the ratio of gonadal to body weight $\times 100$. GSIs of five fish from each reproductive state were averaged and are plotted here. Error bars show SEM.

tween these three groups, suggesting that soma sizes in nonbrooding fish do not constitute a baseline of maturational growth.

An additional possibility exists that irGnRH neurons are not plastic with respect to soma size but that different subsets of cells, for example, one with large somas and another with smaller somas, express GnRH during different reproductive stages. To address this issue, total numbers of irGnRH neurons from sections representing one half of each brain (i.e., one set of alternate sections; see Materials and Methods) were counted and these sums were compared between reproductive groups. Any significant difference between reproductive groups in the total number of irGnRH neurons would suggest that soma size changes could be, at least in part, due to the result of different cell populations expressing GnRH at different times. No significant difference in irGnRH cell number was found either between 1 st brooders and virgins (Mann-Whitney $U=11 ; n_{1}$ $=n_{2}=5 ; p>0.05$ ) or between experienced brooders and experienced spawners $\left(U=6 ; n_{1}=n_{2}=5 ; p>0.05\right)$. This result agrees with previous work on $H$. burtoni males where no difference was found in the total number of irGnRH cells between fish with large GnRH somas (territorial males) and those with smaller cells (nonterritorial males; Davis and Fernald, 1990). While these negative findings do not rule out the possibility that neurons with different soma sizes express $\mathrm{GnRH}$ at different times, in immunoreacted sections counterstained with cresyl violet, cells in the background field surrounding irGnRH somas appear radically smaller in size than even the smallest irGnRH soma (S. A. White and R. D. Fernald, personal obscrvation). Taken together, these observations strongly suggest that statedependent differences in irGnRH soma sizes arise through neuronal plasticity.

\section{Gonosomatic indices}

GSIs were recorded from all fish to confirm that females within the same experimentally defined categories were in similar re- 
Table 2. Summary of statistical analyses on corrected soma sizes

\begin{tabular}{|c|c|c|c|c|c|c|c|c|}
\hline \multirow[b]{2}{*}{ Comparison } & \multirow[b]{2}{*}{ Reproductive states } & \multicolumn{4}{|c|}{ Mann-Whitney } & \multicolumn{3}{|c|}{ Kruskal-Wallis } \\
\hline & & $U$ & $n_{1}$ & $n_{2}$ & 2-tailed $p$ & $\overline{\mathrm{DF}}$ & $H$ & $p$ \\
\hline All subjects & All & & & & & 4 & 18.6 & $0.001^{*}$ \\
\hline \multirow{2}{*}{$\begin{array}{l}\text { Across reproductive class, } \\
\text { within age groups }\end{array}$} & Virgins $\times 1$ st brooders & 3 & 5 & 5 & 0.056 & & & \\
\hline & $\begin{array}{l}\text { Experienced spawners } \times \text { experienced } \\
\text { brooders }\end{array}$ & 0 & 5 & 5 & $0.008^{*}$ & & & \\
\hline \multirow{2}{*}{$\begin{array}{l}\text { Within reproductive class, } \\
\text { across age groups }\end{array}$} & Virgins $\times$ experienced spawners & 4 & 5 & 5 & 0.096 & & & \\
\hline & 1st Brooders $\times$ experienced brooders & 11 & 5 & 5 & 0.842 & & & \\
\hline \multirow{2}{*}{$\begin{array}{l}\text { Across reproductive class, } \\
\text { across age groups }\end{array}$} & Virgins $\times$ experienced brooders & 1 & 5 & 5 & $0.016^{*}$ & & & \\
\hline & 1st Brooders $\times$ experienced spawners & 0 & 5 & 5 & $0.008^{*}$ & & & \\
\hline \multirow[t]{3}{*}{ Older fish } & $\begin{array}{l}\text { Experienced spawners } \times \text { experienced } \\
\text { brooders } \times \text { postreproductive } \\
\text { females }\end{array}$ & & & & & 2 & 10.6 & $0.005^{*}$ \\
\hline & $\begin{array}{l}\text { Experienced spawners } \times \\
\text { postreproductive females }\end{array}$ & 0 & 5 & 3 & $0.036^{*}$ & & & \\
\hline & $\begin{array}{l}\text { Experienced brooders } \times \\
\text { postreproductive females }\end{array}$ & 0 & 5 & 3 & $0.036^{*}$ & & & \\
\hline Nonbrooding fish & $\begin{array}{l}\text { Virgins } \times \text { experienced spawners } \times \\
\text { postreproductive females }\end{array}$ & & & & & 2 & 7.29 & $0.026^{*}$ \\
\hline
\end{tabular}

Comparisons of irGnRH soma sizes from fish in different reproductive states were made using Mann-Whitney $U$ tests for groups of two or Kruskal-Wallis analysis for three or more groups. Asterisks show significant differences $(p<0.05)$.

productive states. GSIs are a direct measure of gonadal weight relative to body weight. They therefore reflect reproductive state independent of age, allowing fish of different ages to be compared, for example, 1st brooders versus experienced brooders. Based on these measurements, we found that 1 st brooders and experienced brooders are in similar reproductive states with low GSIs ( $\leq 1)$. In general, ovaries of these fish contained smaller eggs that were a drab green color and not spherical.

GSIs of virgins and experienced spawners were higher $(>1)$ and more variable. This suggests that these fish are also in a similar reproductive state, although they are not as closely matched as the two sets of brooding fish are. The variability in GSI among virgins could be due to the lack of a precise marker for identifying these fish. (Their selection was based on the observation that they did not have eggs in their mouths; see Materials and Methods.) Thus, this group may include a wider range of maturational states than exists within other categories. Among experienced spawners, GSI depended critically on how many eggs had been laid by the female prior to her capture, as this directly changes ovarian weight. Eggs of spawning fish were generally large, well rounded, and yellow. Finally, postreproductive fish had the lowest GSIs of all, due to the atrophy or, in one case, the apparent absence of ovaries. These results are summarized in Figure 3.

\section{Discussion}

These cell measurements of $H$. burtoni females show that POA irGnRH neurons change significantly in size depending on reproductive state. Specifically, females who have carried broods in their mouths for 2 weeks ( 1 st and experienced brooders) have smaller irGnRH neurons than either virgins, experienced spawners, or postreproductive females. Thus, in reproductively active females, up to a $50 \%$ reduction in cell soma size occurs within a 2 week period. Clearly, soma size reflects the reproductive state of the animal. However, this effect is superimposed on a backdrop of allometric increase in soma size during development: when soma size is not corrected for changes in body length, cells in fish from age class I are smaller than those in age class II. Postreproductive fish, from age class III, had the largest cells. Thus, irGnRH neuron size is plastic with respect both to age and to reproductive state. Interestingly, the magnitude of soma size changes associated with reproductive state is smaller in younger fish. Thus, the difference in mean soma size between virgins and 1 st brooders is less than the difference between experienced spawners and experienced brooders, suggesting that the organizational changes of sex steroids may not be complete at the earlier time points.

There are two possible interpretations of these results. The first is that irGnRH neurons enlarge steadily during development but that some signal deflects them from this trajectory during one part of the reproductive cycle. For example, soma sizes in nonbrooding fish might reflect the baseline of developmental growth from which females with broods deviate. The present findings do not support this interpretation because soma sizes in nonbrooding fish do not fall along a baseline of developmental growth. When compared together, irGnRH neurons in virgins, experienced spawners, and postreproductive fish differ significantly from one another in size. Thus, a range of neuronal sizes are exhibited during the female life-span.

An alternate explanation is that cell size is continuously plastic, both enlarging with age as well as fluctuating cyclically during the reproductive portion of the life history. This intcrprctation gains support when one considers the role that gonadal steroids appear to play in shaping soma size in $H$. burtoni males. Francis 
et al. (1992) have shown that androgens act to limit the growth of irGnRH neurons in the male POA. If estrogens act similarly in females, then different $\mathrm{GnRH}$ soma sizes might reflect different blood estrogen levels. Concentrations of circulating sex steroids are known to fluctuate cyclically with the reproductive cycle in female fish (Liley et al., 1986; Yeung and Chan, 1987; Venkatesh et al., 1990). Thus, there is likely to be a full range of gonadal stcroid fecdback cxerting differential effects on GnRH soma size in reproductively active females. More frequent sampling throughout the cycle would determine whether this is true for $H$. burtoni. Nonetheless, the present study demonstrates robust differences in cell size between spawning and brooding fish, suggesting that the trend toward larger cells during development is overlaid by a cyclically changing soma size, correlated with reproductive state.

In many species, reproductive functions are suppressed by stress (cf. Rivier and Rivest, 1991). In this study, brooding females were briefly handled once during the first few days of brooding in order to stage their eggs (see Materials and Methods). Any stress associated with this manipulation might have affected GnRH neurons. We could not control for this possibility by similarly handling spawning females, as we were unable to identify fish in this reproductive category until the moment they exhibited spawning behavior, at which time they were killed. Since routine handling of all the fish would constitute an even greater stress, we chose to minimize extraneous stress by only handling brooding females for time periods of less than $1 \mathrm{~min}$. While the possibility remains that $1 \mathrm{~min}$ of handling stress could have effects on $\mathrm{GnRH}$ neuron size that persist until death, 10-13 d later, we have not seen such a correlation between brief handling and small soma size in other studies. In ongoing experiments, large irGnRH soma sizes are found in groups of fish that have been frequently handled (White and Fernald, unpublished observations). Thus, it is unlikely that handling stress accounts for the observed decrease in GnRH soma size reported here for brooding females.

At present, little is known about cytoarchitectural changes that cause expansion and contraction of neurons. At the light microscopic level, larger irGnRH neurons do not appear different in shape from smaller ones. Thus, passive swelling due to fluid edema is unlikely. However, subtler changes in morphology may be lost or obscured by the tissue processing techniques used here. Ultrastructural studies of arcuate neurons in female rat hypothalami have revealed cyclical changes in perikaryon size associated with increased endoplasmic reticulum and number of granulated vesicles (Zambrano, 1969; King and Williams, 1974; Tsuruo et al., 1984). Thus, neuronal hypertrophy may correlate with an upregulation of the neurosecretory apparatus. Ultrastructural studies of the irGnRH neurons described here are currently underway.

The functional significance of cell size changes in the POA may lie in the delivery of the GnRH peptide to the pituitary. For example, enlargement of GnRH-containing cells at the initiation of spawning may serve to increase the pulsatile release of the peptide. This would stimulate the pituitary release of gonadotropins into the bloodstream leading to the preovulatory surge in estradiol (Liley et al., 1986; Yeung and Chan, 1987; Venkatesh et al., 1990). Conversely, smaller GnRH soma sizes in brooding fish may reflect a decrease in the amount or frequency of GnRH release and lower gonadotropin and estrogen levels, consistent with the small ovaries and immature eggs observed in these fish (Nagahama, 1990). A positive correlation between GnRH soma size, GnRH peptide, and plasma gonadotropin levels in $H$. burtoni remains to be demonstrated. More generally, in developmental studies on the platyfish, Xiphophorus maculatus, the appearance of larger POA GnRH neurons is temporally linked with the onset of sexual development (Schreibman and Margolis-Nunno, 1989), suggesting that increased GnRH soma size reflects increased GnRH activity. Finally, in addition to changes in ncurosecretory output, cnlarged neuronal soma size could correlate with heightened input since a larger target area is afforded to potential synapses (Arnold and Breedlove, 1985).

irGnRH neurons in the POA of $H$. burtoni appear to have regulatory dimorphisms. While GnRH soma size is correlated with both social and reproductive state in males, social cues are primary since switching the social state of a male through experimental manipulation precipitates changes in GnRH neuron size (Francis et al., 1992). Among reproductively active females, however, soma size may be regulated differently, corresponding to a cyclical pattern of activation. These females show little evidence of social hierarchy. The most obvious social stimulus to the female is the courting male, which may include visual, physical, or chemical cues. As in other fishes (Stacey et al., 1979; Moore, 1987), additional environmental factors such as water quality and temperature, and availability of a spawning substrate could also serve to prime the $H$. burtoni female for spawning and thereby initiate changes in soma size. However, unlike males, reproductive females school together and are consequently all exposed to approximately the same stimuli, including male soliciting behavior. Whether a female then leaves the school and follows the male to the nesting site to spawn would seem to depend on her internal state. Thus, while external cues may be necessary for the persistence of the female reproductive cycle, we find no clear evidence that they trigger the observed changes in neuron size comparable to the social cues in males. A more careful investigation of how long females continue to cycle in the absence of males or of which social and environmental components suffice for full reproductive activity is warranted.

Factors regulating the postreproductive state in female $H$. burtoni are undetermined. The minuscule ovaries of postreproductive fish are indicative of low estradiol levels. Thus, as in male castrates, the large GnRH cells in these fish are presumably due to loss of inhibitory feedback from sex steroids (Francis et al., 1992). Such an effect has been described for infundibular neurons in postmenopausal women (Rance et al., 1990). What leads to ovarian atrophy in these fish is not known, but two observations may be relevant: first, not all nonreproducing females exhibit the territorial behaviors described here for postreproductive fish; second, postreproductive fish are generally larger than other females and are equivalent to or larger than males. Thus, either external social cues (e.g., relative body size) or internal maturational processes (e.g., aging) could mediate the switch in neuroendocrine status.

In summary, this study demonstrates that $\mathrm{GnRH}$ neurons within the POA of $H$. burtoni females change in size during the reproductive cycle. Females that have brooded their progeny for 2 weeks have smaller irGnRH neurons than animals that have never spawned or those in the act of spawning. Postreproductive females exhibit the largest soma sizes. Thus, the POA GnRH neuronal population is pleiomorphic in both female and male $H$. burtoni, but the regulatory signals governing cell size plasticity differ with gender. In females, cyclical activation during reproductive maturity seems primarily governed by an en- 
dogenous program. In males, exogenous cues predominate to alter reproductive state according to social status. In both sexes, steroids exert activational effects in the mature animal by structural mechanisms. As cited above, a variety of sexually dimorphic nuclei have been studied in vertebrates. The present work on $H$. burtoni, however, is the first to show plasticity of neuronal soma size within both sexes, which appears to exhibit regulatory dimorphisms corresponding to social status in males (Francis et al., 1992) and reproductive state in females. The cellular mechanisms by which these changes occur as well as the significance of this type of regulation invite further study.

\section{References}

Araki I, Harada Y, Kuno M (1991) Target-dependent hormonal control of neuron size in the rat spinal nucleus of the bulbocavernosus. J Neurosci 11:3025-3033.

Arnold AP (1984) Androgen regulation of motor neuron size and number. Trends Neurosci 7:239-242.

Arnold AP, Breedlove SM (1985) Organizational and activational effects of sex steroids on brain and behavior: a reanalysis. Horm Behav 19:469-498.

Breedlove M (1986) Cellular analyses of hormone influence on motoneuronal development and function. J Neurobiol 17:157-176.

Davis MR, Fernald RD (1990) Social control of neuronal cell size. J Neurobiol 21:1180-1188.

Fernald RD (1977) Quantitative behavioural observations of Hap lochromis burtoni under semi-natural conditions. Anim Behav 25: 643-653.

Fernald RD, Hirata N (1977) Field study of Haplochromis burtoni under semi-natural conditions. Environ Biol Fishes 2:299-308.

Francis RC, Jacobsen B, Wingfield JC, Fernald RD (1992) Hypertrophy of gonadotropin releasing hormone-containing neurons after castration in male Haplochromis burtoni. J Neurobiol, in press.

Frankfurt M, Gould E, Woolley CS, McEwen BS (1990) Gonadal steroids modify dendritic spine density in ventromedial hypothalamic neurons: a Golgi study in the adult rat. Neuroendocrinology 51 : 530-535.

Garcia-Segura LM, Hernandez P, Olmos G, Tranque PA, Naftolin F (1988) Neuronal membrane remodelling during the oestrus cycle: a freeze-fracture study in the arcuate nucleus of the rat hypothalamus. J Neurocytol 17:377-383.

Gurney ME (1981) Hormonal control of cell form and number in the zebra finch song system. J Neurosci 1:658-673.

Hagedorn M, Fernald RD (1992) Retinal growth and cell addition during embryogenesis in the teleost, Haplochromis burtoni. J Comp Neurol 321:193-208.

Harris G (1964) Sex hormones, brain development and brain function. Endocrinology 75:627-648.

Kelley DB, Tobias ML (1989) The genesis of courtship song: cellular and molecular control of a sexually differentiated behavior. In: Perspectives in neural systems and behavior (Carew TJ, Kelley DB, eds), pp 175-194. New York: Liss.

King JC, Williams TH (1974) Transformations of hypothalamic arcuate neurons. Cell Tissue Res 153:497-515.
Konishi M, Akutagawa E (1985) Neuronal growth, atrophy and death in a sexually dimorphic song nucleus in the zebra finch. Nature 315: $145-147$.

Konishi M, Akutagawa E (1990) Growth and atrophy of neurons labeled at their birth in a song nucleus of the zebra finch. Proc Natl Acad Sci USA 87:3538-3541.

Liley NR, Fostier A, Breton B, Tam ESP (1986) Endocrine changes associated with spawning behavior and social stimuli in a wild population of rainbow trout (Salmo gairdneri). Gen Comp Endocrinol 62:157-167.

McEwen BS, Coirini H, Westlind-Danielsson A, Frankfurt M, Gould E, Schumacher M, Woolley C (1991) Steroid hormones as mediators of neural plasticity. J Steroid Biochem Mol Biol 39:223-232.

Moore FL (1987) Regulation of reproductive behaviors. In: Hormones and reproduction in fishes, amphibians and reptiles (Norris DO, Jones RE, eds), pp 505-522. New York: Plenum.

Naftolin F, Garcia-Segura LM, Keefe D, Leranth C, Maclusky NJ, Brawer JR (1990) Estrogen effects on the synaptology and neural membranes of the rat hypothalamic arcuate nucleus. Biol Reprod 42:21-28.

Nagahama Y (1990) Endocrine control of oocyte maturation in teleosts. In: Progress in comparative endocrinology (Epple A, Scanes CG, eds), pp 385-392. New York: Wiley-Liss.

Pfaff DW, McEwen BS (1983) Actions of estrogens and progestins on nerve cells. Science 219:808-814.

Phoenix C, Goy R, Gerall A, Young W (1959) Organizing action of prenatally administered testosterone propionate on the tissues mediating mating behavior in the female guinea pig. Endocrinology 65 : 369-382.

Rance NE, McMullen NT, Smialek JE, Price DL, Young WS III (1990) Postmenopausal hypertrophy of neurons expressing the estrogen receptor gene in the human hypothalamus. J Clin Endocrinol Metab 71:79-85.

Rivier C, Rivest S (1991) Effect of stress on the activity of the hypothalamic-pituitary-gonadal axis: peripheral and central mechanisms. Biol Reprod 45:523-532.

Schreibman MP, Margolis-Nunno H (1989) The brain-pituitary-gonad axis in poikilotherms. In: Development, maturation, and senescence of neuroendocrine systems: a comparative approach (Schreibman MP, Scanes CG, eds), pp 97-133. Berkeley: Academic.

Siegel S (1956) Nonparametric statistics for the behavioral sciences. New York: McGraw-Hill.

Stacey NE, Cook AF, Peter RE (1979) Spontaneous and gonadotropininduced ovulation in the goldfish, Carassius auratus: effects of external factors. J Fish Biol 15:349-361.

Tsuruo T, Hisano S, Okamura Y, Tsukamoto N, Daikoku S (1984) IIypothalamic substance P-containing neurons. Sex-dependent topographical differences and ultrastructural transformations associated with stages of the estrous cycle. Brain Res 305:331-341.

Venkatesh B, Tan CH, Lam TJ (1990) Steroid hormone profile during gestation and parturition of the guppy (Poecilia reticulata). Gen Comp Endocrinol 77:476-483.

Yeung WSB, Chan STH (1987) The plasma sex steroid profiles in the freshwater, sex-reversing teleost fish, Monopterus albus (zuiew). Gen Comp Endocrinol 65:233-242.

Zambrano D (1969) The arcuate complex of the female rat during the sexual cycle. An electron microscopic study. Z Zellforsch Mikrosk Anat 93:560-570. 